\title{
A growing interest for intellectual property in universities
}

\author{
"In this evolution of the role of universities within the Knowledge Society, it is \\ desirable to see higher education institutions develop in a way that does not \\ compromise their primary aims."
}

\begin{abstract}
Keywords: anticommons $\bullet$ biotechnology $\bullet$ technology transfer office (TTO) $\bullet$ triple helix - university
\end{abstract}

Universities represent, historically, the highest organization responsible for the generation and diffusion of knowledge; teaching and research are thus the primary purposes of every academic institution. Knowledge, on the other hand, can be monetized, and one way to do so is through innovative technologies. Novelty brings progress and competitive advantage through ownership of intellectual property (IP) rights, thus driving higher education institutions (HEIs) into a new function: the producer of innovation.

The most significant change in the role of universities within the IP landscape is relatively recent and can be identified with the Bayh-Dole Act, proposed in 1980 and granting US academic institutions direct ownership over their IP. About a decade later, the Triple Helix concept further defined such role. This thesis envisions a more prominent position of HEIs in the Knowledge Society: a proactive university (the 'Entrepreneurial University') establishing stronger interactions with the other two fundamental entities on a national and international level, industry and government. The university-industry relationship is particularly important, since the latter becomes the main recipient of the more IP-focused academic research, as well as potential backer or partner.

This vision led to increased pressure over universities to monetize their IP, resulting in a growing number of academic IP filings worldwide. Although the IP field is still dominated by industries, HEIs have shown a steady increase in patent filings over the last decade. WIPO data show a rather constant increase in university PCT applications, with a $3.0 \%$ increase in the share of patents filed by university applicants within the period 2007-2011 (calculated as average of yearly increases over the period), a trend that looks set to continue [1].

High-tech areas such as biotechnology tend to be very strong sectors for university IP: recent WIPO analyses show how biotech stands right behind pharmaceuticals in the share of academic-developed technologies leading to PCT applications (15.7\% of share on the total university PCT applications for pharma vs $13.4 \%$ in biotechnology), and is the first of the top five academic technologies when considering its share in comparison with business applicants (university/business share ratio is 4.7 for pharma and 6.2 for biotechnology) [2].

The prominent role of biotechnology in the academic landscape is a consequence of the multidisciplinary and heavily researchbased nature of this discipline, thus making HEIs very fitting candidates for the generation of new biotech IP [3]. Thanks to its wide coverage of methodologies and applications, biotechnologies can find many uses, but its IP opportunities largely overlap with those of the pharmaceutical sector. Biopharmaceuticals can provide alternatives to existing therapies as well as new ones, leading to an 'invasion' of the pharmaceutical field, originally constituted by small molecule patents. The higher costs of biopharmaceuticals, however, is a major slowdown making its way to the market, and future rulings on the patentability of new biotechnology inventions could also

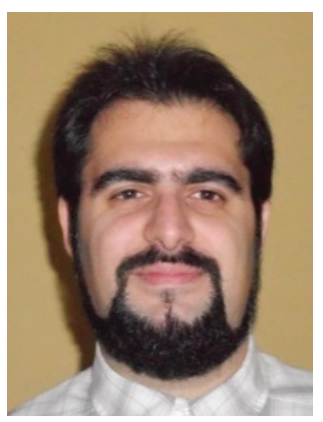

Aristotele Karytinos Università Degli Studi di Pavia, 27100 Pavia, Italy

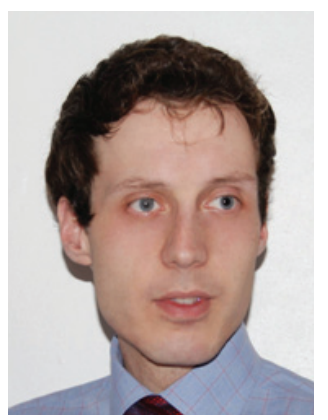

Andrew Ingham Author for correspondence: Aston University, Aston Triangle, Birmingham, B4 7ET, UK inghamaj@aston.ac.uk 
skew this trend. What is less likely to change is the tendency of big pharma companies to partner with, or acquire biotechnology IP from small, innovation-rich biotech firms and research-intensive HEIs.

To support this new role, HEIs need to develop an adequate managerial structure. This goal is being achieved through university technology transfer offices (TTOs), responsible for mediating the interaction between university, industry and the IP machinery. Yet the gap between academia and business is difficult to fill: TTOs are still relatively young and climbing a learning curve of best practices in patent protection, adding to the intrinsic difficulties linked to the different needs and priorities of these two entities. As effectively described by Peter Saraga for the UK government Department for Innovation, Universities and Skills, while universities are more concerned with scholarly freedom, compliance to public funding and prestige derived from publications, industries are more interested in the value of IP and commercial freedom [4]. These differences potentially lead to complications in managing the university-industry interaction; in particular, it has been observed that $34 \%$ of UK academics perceive difficulties in negotiating the terms of such interaction if IP is involved, when considering the most research-intensive HEIs [5].

From the industry viewpoint, the top three issues seem to be: the long-term orientation of academic research, the potential issues related to royalty payments and confidentiality, and university and government funding regulations [6]. While the first of these problems is bound to the original role of universities, which privileges the intellectual significance of discoveries rather than their commercial use, the other two are tied to the sometimes cumbersome academic bureaucracy and the desire of firms to gain more control over IP. On the university side, one possible path to smooth at least part of these asperities is to clearly define contractual terms in advance, creating standard contract options particularly for underdeveloped technologies.

Bridging university and business is clearly a goal requiring efforts on both parts, but while the gain for industries is evident, what do universities earn from this synergy? The most obvious reward is purely economical: interacting with industries can open new possibilities in terms of additional funding and partnerships. This collaboration can also enrich HEIs on a cultural level, particularly in the education of undergraduate and graduate students who come in contact with real-world experiences and could be better mentored in their career choices by a faculty with strong ties with industry. On the other hand, such interaction can limit academic freedom and lead to a decrease in pure research.
These drawbacks, together with the redirection of academic efforts into the 'third mission', are causes of concern as they can ultimately have an impact on the original societal role of HEIs. Universities are moving from an 'open science' paradigm to a more commercial orientation [7]. Imposed publication delays and other constraints set to protect IP can impair the circulation of new knowledge and may contribute to an overall 'anticommons effect'. For example, it has been observed that forward citations of papers included into a patent-paper pairs decrease after the associated patent is granted, and this effect is increased where there is a greater elapsed time since the patent granting. It is particularly evident for universities and public institutions [8]. Social implications are particularly significant for pharmaceutical patents, given their impact on global health. Empirical studies have shown that while patenting is curiously unimportant for appropriating returns on $\mathrm{R} \& \mathrm{D}$ in most industry sectors, it is considered fundamental in pharma, as IP protection compensates for the lengthy and expensive procedures needed to bring drugs to the market, which contrast the relatively low costs of imitation [9]. Protection, on the other hand, leads to monopoly pricing, with effects such as denying access to a cure in some countries. Besides the downturn in pharmaceuticals patent applications by HEIs, universities perform a fair amount of base research leading to new drugs, and in the past have proven to be able to affect global health: the most notable example is probably the one of stavudine, patented by Yale University in 1990 for HIV treatment.

In this evolution of the role of universities within the Knowledge Society, it is desirable to see HEIs develop in a way that does not compromise their primary aims. Universities have a unique, undisputed role in the knowledge economy as generators of highly trained human capital and inquirers of fundamental scientific problems, necessary for further technological development and overall public good. Projecting themselves toward innovation can bring important benefits to HEIs, as it offers academics a stronger contact with what will be the applications of knowledge, but should not undermine their main societal functions. TTOs often find themselves under conflicting directives and tend to pursue different objectives for individual researchers, with a more patent- and revenue-centric imprint rather than following the rout of public access. In absence of specific regulations and given the necessity to evaluate patenting and licensing issues on a caseby-case basis, it is up to technology transfer managers to identify the right compromise to conciliate public and private sectors. 


\section{Financial \& competing interests disclosure}

The authors have no relevant affiliations or financial involvement with any organization or entity with a financial interest in or financial conflict with the subject matter or materials discussed in the manuscript. This includes employment,

\section{References}

1 World Intellectual Property Organization (WIPO) statistics centre. World Intellectual Property Organization, 34, chemin des Colombettes, Switzerland. www.wipo.int/ipstats/en

2 Patent Cooperation Treaty Yearly Review, WIPO, July 2014. www.wipo.int/edocs/pubdocs

3 Zilberman D, Heiman A. University research and offices of technology transfer. California Management Review 45(1), 88-115 (2002).

4 Saraga, P. Streamlining university/business collaborative research negotiations. An independent report to the "Funders' Forum" of the Department for Innovation Universities and Skills (2007).

http://dera.ioe.ac.uk/6743/1/streamlining-august07.pdf

5 Moore B, Ulrichsen T. The intellectual property regime and its implications for knowledge exchange. A report to HEFCE consultancies, honoraria, stock ownership or options, expert testimony, grants or patents received or pending, or royalties.

No writing assistance was utilized in the production of this manuscript.

by PACEC and the Centre for Business Research, University of Cambridge (2010)

www.pacec.co.uk/publications

6 Bruneel J, D'Este P, Salter A. Investigating the factors that diminish the barriers to university-industry collaboration. Research Policy 39(7), 858-868, (2010).

7 Baca MR. Barriers to innovation: intellectual property transaction costs in scientific collaboration. Duke Law \& Technology Review 4-20 (2006).

8 Murray F, Stern S. Do formal intellectual property rights hinder the free flow of scientific knowledge?: an empirical test of the anti-commons hypothesis. Journal of Economic Behavior \& Organization 63(4), 648-687 (2007).

9 Ouellette LL. How many patents does it take to make a drug? Follow-on pharmaceutical patents and university licensing. Michigan Telecommunication Technology Law Review 17, 299 (2010). 